\title{
A New Strategy and System for the Ex Vivo Ovary Perfusion and Cryopreservation
}

Mohamed SA Mohamed*

*Corresponding author: Mohamed SA Mohamed, Deutz-Kalker Str. 118, 50679, Cologne, Germany, Tel: +4915214736574; E-mail: Mohammed.shehatta1@gmail.com

Received date: April 14, 2017; Accepted date: April 24, 2017; Published date: May 01, 2017

Copyright: (C) 2017 Mohamed MSA. This is an open-access article distributed under the terms of the Creative Commons Attribution License, which permits unrestricted use, distribution and reproduction in any medium, provided the original author and source are credited.

\begin{abstract}
Childern and young adults, who suffer from cancer, receive gonadotoxic therapy, which destroys their fertile abilities after survival. Ovarian cryopreservation and transplantation provides the promising solution to this problem, where the ovary can be removed before the gonadotoxic therapy and reimplanted after patient's survival, where the ovary is to be cryopreserved during the period of the therapy. However, cryopreservation of the whole ovary is still facing great obstacles, namely the ischemic reperfusion injury and the defective cryopreservation related to the defective ability to universally deliver the cryopreservation/warming solutions through the ovarian vascular bed. Meanwhile, the currently applied technique of ovarian tissue cryopreservation provides limited follicular recovery because many follicles are lost until the development of revascularization post-transplantation.
\end{abstract}

To solve these problems, an innovative system has been developed to insure immediate and universal delivery of the cryopreservation/warming solutions to the graft, in addition to keeping the graft under continuous perfusion before and after cryopreservation, minimizing any chance for microthrombi fomation or ischemia- reperfusion. This innovative system can be applied in the following surgical and clinical interventions:

1. Allogeneic ovarian transplantation

2. Preservation of fertility after systemic chemotherapy or bone marrow transplantation in young females, where the ovaries could be removed before the therapy and exposed to the adequate cryopreservation provided by the system till re-implantation after the patient's survival.

3. The system is also suitable for corresponding applications on the testicles.

Keywords: Ex vivo ovary perfusion; Ovary cryopreservation; Gonadotoxic cancer therapy; Fertility preservation; Premature ovarian failure

\section{Introduction}

Ovarian cryopreservation aims at the preservation of fertility in young women subjected to gonadotoxic anti-cancer therapy. It is also important for women undergoing hematopoietic stem cells transplantation and other reasons of premature ovarian failure. Further indications could differ from country to another, based on the available medical regulations [1,2].

Ovarian cryopreservation can be performed using the slow freezing technique, where a programmable controlled temperature change can be applied, or the vitrification technique, where the ovarian tissue is equilibrated with suitable concentrations of cryoprotectants and directly plunged into liquid nitrogen $[3,4]$.

Recently, ovarian cryopreservation has been tried with animals [5] and humans [6] applying both slow freezing [7-14] and vitrification techniques, [14-22] with the results of vitrification are comparable to those of slow freezing [14].

Ovarian cryopreservation is considered important rather than mature oocyte or embryo cryopreservation because it preserves the hormonal and fertility functions following cancer therapy. In addition, the cryopreservation of oocytes or embryos is not always possible before cancer therapy in cases of prepubertal girls, hormone- sensitive tumors, or because of the lack of a partner and or enough time $[23,24]$.

The ovary is composed of the cortex, which is the outer part and contains tightly packed connective tissue, and the medulla, which is central and highly vascular. The majority of the follicles, in varying stages of maturation, is located in the cortex, including the primordial follicles that require the signal for further development. In the currently applied protocols, the cortex is dissected from the medulla and subjected to cryopreservation, where many primordial follicles are present. This technique is associated with less injury rather than the cryopreservation of individual oocytes and or embryos. This may be related to the smaller size and the slower metabolic rates of the primordial follicles. In addition to the absence of zona pellucida and the in vivo follicular maturation following transplantation [25]. Accordingly, the ovarian cortex is the actual part subjected to cryopreservation, following the sharp dissection from the medulla.

After the successful cancer therapy, the thawed ovarian cortex is transplanted close to the fallobian tube, allowing the in vivo maturation of the primordial follicles and the restablishment of the hormonal and the fertilizing functions of the ovary [26-30].

Current techniques in ovarian cryopreservation

Cryopreservation is the process, where biological materials, cells and tissues are preserved in sub-zero temperatures to be retrieved 
through warming in the subsequent future. At such very low temperatures, the enzymatic activities that could damage the cell is stopped. The success of the cryopreservation depends on the use of certain compounds that protect the cells (hence, called cryoprotectants) as well as the cooling rate [31].

\section{Cryoprotectants can be divided into 2 major categories:}

- Permeable cryoprotectants that have the ability to penetrate the cell membrane and, accordingly, protect against the intracellular ice formation. The use of permeable cryoprotectants is associated with significant toxicity and extra-stress on the cell during their addition and removal, before freezing and after thawing, respectively [32].

- Non-permeable cryoprotectants that cannot penetrate the cell membrane and, accordingly, protect against the extracellular ice formation [33].

Ovarian cryopreservation could be achieved through the slow freezing (programmable) rate or the ultra-rapid freezing rate (vitrification). Vitrification is the technique, where the cells/tissues are frozen at an ultra-rapid rate by direct plunging into liquid nitrogen, where the cells suspension change into a glass-like solidification, avoiding ice crystal formation [34]. Rapid rates of freezing don't allow the permeable cryoprotectants to exert their protective actions, which essentially require slow cooling rate. Meanwhile, the non-permeable cryoprotectants stabilize the cells during the ultra-rapid freezing [35].

Slow freezing of the ovarian tissue starts with the cutting of the ovarian cortex into strips, as an initial step. An example of a protocol could be as following, where the cortical strips are suspended in a cryoprotective solution at $4^{\circ} \mathrm{C}$. The strips are then to be transferred to 2 $\mathrm{mL}$ cryovials, containing $0.8 \mathrm{~mL}$ cryoprotective solution that are to be cooled in a programmable freezer from $0^{\circ} \mathrm{C}$ to $-8^{\circ} \mathrm{C}$ at $-2^{\circ} \mathrm{C} / \mathrm{min}$, then to be cooled to $-40^{\circ} \mathrm{C}$ at $-0.3^{\circ} \mathrm{C} / \mathrm{min}$. This is followed by cooling to $-140^{\circ} \mathrm{C}$ at $-30^{\circ} \mathrm{C} / \mathrm{min}$ and transfer to liquid nitrogen $\left(-196^{\circ} \mathrm{C}\right)$ for storage.

The programmable freezing might be performed manually by placing the cryovials in the nitrogen vapor before plunging into the liquid nitrogen, where the temperature of the vapor depends on the distance between the vials and the surface of the liquid as well as on the amount of the used liquid nitrogen. However, the control of the cooling rates in this case would be difficult [36].

For thawing, the cryovials are simply placed in room temperature for 2 minutes, and then in a $37^{\circ} \mathrm{C}$ water bath till the ice completely melt. Before transplantation, the ovarian tissue is placed in plastic petri dishes containing minimal essential medium (MEM), supplemented with Glutamax, for washing. The washing is to be performed, at least, for three times (5 minutes each) to get rid of the cryoprotectants [36].

Vitrification of the ovarian tissue starts with the cutting of the ovarian cortex into cubes, as an initial step. Two protocols could be examples for ovarian tissue vitrification:

- Protocol 1, where the vitrification solution, which contains $20 \%$ DMSO, 20\% ethylene glycol in MEM, supplemented with 25 $\mathrm{mg} / \mathrm{mL}$ human serum albumin (HSA), is used. The ovarian cubes are to be equilibrated in $25 \%$ vitrification solution for 5 minutes (at $4^{\circ} \mathrm{C}$ ), followed by equilibration in $50 \%$ vitrification solution for another 5 minutes (at $4^{\circ} \mathrm{C}$ ), and finally in $100 \%$ vitrification solution for 10 minutes (at $4^{\circ} \mathrm{C}$ ). Following equilibration, the ovarian cubes are to be placed on aseptic absorbent gauze to remove the remaining vitrification solution. The cubes are then transferred to a stainless steel box, partially immersed in liquid nitrogen. Now the ovarian fragments are vitrified and are to be placed in pre-cooled cryovials for long term storage in liquid nitrogen [37].

- Protocol 2, where the vitrification solution is composed of $10 \%$ DMSO and 26\% ethylene glycol in MEM, supplemented with 20 $\mathrm{mg} / \mathrm{mL}$ HSA, $2.5 \%$ polyvinylpyrrolidone and $1 \mathrm{~mol} / \mathrm{L}$ sucrose. The ovarian cubes are to be equilibrated in $25 \%$ vitrification solution (for 5 minutes), then in $50 \%$ vitrification solution (for 5 minutes), and finally in $100 \%$ vitrification solution (for 1 minute), at room temperature. After equilibration, the cubes are to be placed on an aseptic absorbent gauze at room temperature, in order to remove the remaining vitrification solution. The cubes are then to be placed in open cryostraws, and to be plunged into liquid nitrogen. Now the ovarian fragments are vitrified and are to be placed in pre-cooled cryovials for long term storage in liquid nitrogen $[33,38]$.

For warming of the vitrified ovarian tissue, the ovarian strips or cubes are taken out from the cryovials and placed into warming solution 1 at $37^{\circ} \mathrm{C}$, which is composed of $1 \mathrm{~mol} / \mathrm{L}$ sucrose in MEM, supplemented with $25 \mathrm{mg} / \mathrm{mL}$ HSA. The tissue is to be incubated in this solution for about 15 seconds, and then to be transferred to the warming solution 2 (which has the same composition of warming solution 1, apart from $0.5 \mathrm{~mol} / \mathrm{L}$ sucrose concentration), followed by warming solution 3 (which has the same composition of warming solution 1, apart from $0.25 \mathrm{~mol} / \mathrm{L}$ sucrose concentration), and warming solution 4 (which has the same composition of warming solution 1, apart from $0 \mathrm{~mol} / \mathrm{L}$ sucrose concentration), for 5 minutes at $37^{\circ} \mathrm{C}$ each $[33,37,38]$.

Several studies have reported successful results of transplantation of cryopreserved ovarian tissues of both techniques, with the results of vitrification being superior or, at least, comparable to those of slow freezing [33]. However, and regardless of the technique of cryopreservation, there are two major problems hindering the transplantation of the ovarian tissue and limiting the graft survival; the cryoinjury in case of cryopreservation, and the ischemic reperfusion injury.

As the ovarian cortex is composed of tightly packed connective tissue, where it depends on the underlying highly vascular ovarian medulla for getting the necessary oxygen and nutrient supplies, it takes a relative longer time (2-3 days) to re-establish adequate vascular connections with the underlying tissue following transplantation, which leads practically to some degree of follicular atrophy and failure of long term graft survival. This is why the peritoneal grafting of the ovarian tissue has been associated with better results than the subcutaneous grafting, as the revascularization in the peritoneal case is better. However, in all cases, a large number of follicles would be ultimitly lost until the neovascularization occurs, accordingly, there would be a high risk of graft failure [39,40].

Many strategies have been tried to minimize the posttransplantation ischemic ovarian damage, however, these strategies lack the standardization, the reproducibility and the long term success [41]. Examples of those strategies are:

- Mechanical induction of neoangiogenesis, through the induction of tissue injury and grafting the ovarian tissue on the being formed granulation tissue [42].

- The use of antioxidants [43-45].

- The use of neoangiogenesis - inducing growth factors [46]. 
- The use of hormonal therapy [47].

Nevertheless, a promising solution for that problem is the whole ovary transplantation, where the ovrian vascular pedicle is anastomosed during transplantation, using microvascular surgery [48].

Although this strategy provides a very promising theoretical solution, which can be applied for both fresh and frozen/thawed ovaries, and can significantly minimize the ischemic injury after transplantation, there are still major troubles facing it [49-52]:

1. The ability to efficiently cryopreserve the whole ovary, instead of the ovarian tissue fragments. The main obstacles of this procedure are the intravascular thrombosis and the inability to efficiently deliver the cryopreservation and warming solutions simultaneously to the whole ovary.

2. The complexity of the surgical procedure and the ischemic reperfusion injury associated with all solid organs transplantation.

To overcome those problems, the following innovative technique is introduced to improve the ovarian cryopreservation and transplantation clinical outcome.

\section{The innovative ex vivo ovary perfusion model of shehata}

In the present technique, the donor ovary, which belongs to the cancer patient herself or the matching donor for cases of ovarian failure, is removed by a labaroscopic or an open surgical approach, where the vascular pedicle of the ovary is accessed. The ovarian artery is approached as proximal as possible, and catheterized after giving off its branches. Similarly, the ovarian vein is approached as distal as possible, and catheterized before receiving its tributaries.

Now, the donor ovary can be surgically removed, while both the vascular input and output are catheterized, however, before removal, in vivo perfusion through the catheters is to be performed for few minutes, to avoid ischemia and any risk of microthrombi formation. The arterial and venous catheters are connected to a circuit of perfusion, composed of the following (Figure 1):

- A box to enclose the ovary and can be used as a sealed cryovial.

- The box enclusing the ovary can work as a sealed cryovial, which allows the passing of the perfusion input and output catheters during perfusion, and the complete sealing during liquid nitrogen storage.

- The circuit itself is made of perfusion tubes, connected to the arterial and venous catheters.

- Reservoirs to introduce and remove the perfusates (perfusion supplemented medium, cryopreservation and warming solutions).

- A pulsatile or continous flow centrifugal pump, providing flow equivilant to the estimated physiological ovarian artery flow of the donor (pre-cryopreservation) and of the receipent (postcryopreservation).

- A set of leukocytes and cytokines filters.

- A temperature adjustor that can control the temperature of the perfusate.

- A gas exchanger to remove $\mathrm{CO} 2$ and provide $\mathrm{O} 2$, to maintain these gases in the perfusate at the physiological levels.

- The whole system will be placed on a portable mobile base, to allow the transport of the ovary from the donor hospital to the cryopreservation center and or the recipient hospital while perfused, in order to avoid warm ischemia.

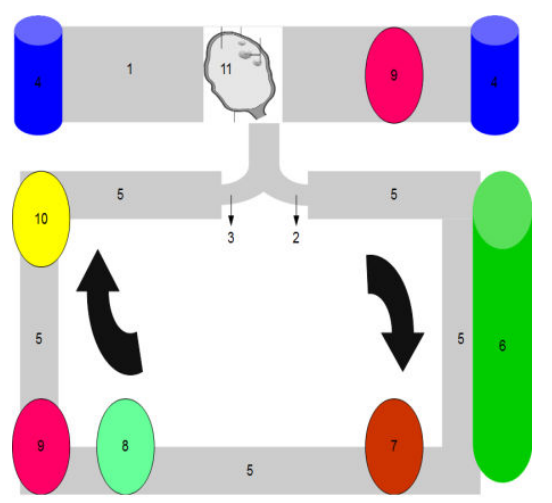

Figure 1: Diagrammatic representation of the ex vivo ovary perfusion system.

1. A box to enclose the ovary and works as a sealed cryovial.

2. Ovarian vein stump connected to the circuit, using a special cannula or catheter (perfusion output).

3. Ovarian artery stump connected to the circuit, using a special cannula or catheter (perfusion input).

4. Reservoirs for filling the ovary-containing box with medium, the cryoprotective, vitrification, and warming solutions during cryopreservation.

5. The perfusion circuit.

6. Perfusate reservoir.

7. Centrifugal pump (pulsatile or continuous flow).

8. Set of leukocytic and cytokines filters.

9. Temperature adjustor.

10. A gas exchanger to remove $\mathrm{CO}_{2}$ and provide $\mathrm{O}_{2}$, to maintain these gases in the perfusate at the physiological levels.

11. The ovary graft inside the cryovial/ perfusion box.

The introduced procedure starts with the surgical retrieval of the donor ovary, where vascular catheterization and immediate perfusion begins. The used perfusate can vary according to the protocol used, for instance, minimal essential medium (MEM) supplemented with HSA or human tubal fluid medium supplemented with serum substitute supplement (SSS). Further supplementation could be considered according to the used protocol, such as ascorbic acid, antioxidants, hormones, growth factors, antibiotics, heparin, etc.

The immediate and continuous perfusion minimizes the risk of microthrombi formation, however, thrombolytic medications could be supplemented to the perfusate, in order to dissolve any formed microthrombi. At this stage, the donor ovary has not manifested significant ischemia or oxygen or nutrient deprivation, and the vascular bed is clearly accessible.

In case of fresh ovary transplantation, the ovary could be kept perfused under normothermic or hypothermic conditions till transplantation and intraoperative vascular anastomosis, allowing the chance of gross and or microscopic assessment of the graft, when needed. In this case, the ischemic reperfusion injury would be significantly minimized. 
Page 4 of 5

However, in case the cryopreservation of the ovary is planned, the cryopreservation solution (either for slow freezing or for vitrification) can be introduced into the circuit to simultaneously fill the cleaned vascular bed of the ovary and the plastic box around the graft. This ability, together with the presence of temperature adjustors, allow the application of the cryopreservation or vitrification protocol of interest (as previously described), where at the end, the graft can be stored in liquid nitrogen. These abilities of the system allow, as well, the application of the warming protocols (as previously described), where the graft can be further perfused till the surgical transplantation, minimizing the ischemic reperfusion injury.

\section{The innovation in shehata's ovary system}

As previously discussed, the wohle ovary cryopreservation has been introduced and experimentally tested [41]. In addition, the idea of $e x$ vivo perfused ovary was used before in some experimental studies for the ex vivo culture of the wohle ovary, in order to allow the ex vivo oocyte maturation and development. However, to the best of my knowledge, it is the first time to introduce the ex vivo perfusion technique as a procedure that should precede and follow the cryopreservation of the ovary, in order to overcome the obstacles that limit the success of the technique.

Moreover, the introduced system is very unique, allowing the application of both ex vivo perfusion and cryopreservation in one system, which ensures better and simultaneous delivery of the cryoprotective and warming solutions to the inside and the outside of the organ, allowing for better outcome of the procedure.

\section{Clinical applications and intended use of the proposed system}

The proposed system can be applied in the following surgical and clinical interventions:

1. Allogeneic ovarian transplantation, where the system will allow the ex vivo organ perfusion, minimizing the ischemic reperfusion injury and allowing graft investigation and conditioning before transplantation. In this case, the set of leukocytic and cytokine filters are included to filter the donor leukocytes and minimize the hazards of the ischemic reperfusion injury.

2. Localized treatment of ovarian cancers without exposing the patient to the systemic hazards of chemotherapy and radiotherapy, where the affected ovary could be surgically isolated from the patient's body and circulation, and kept under perfusion in the system, while localized and highly concentrated doses of chemo- and or radiotherapy could be applied to target the cancer cells within the ovary (to preserve fertility, if some healthy tissue and follicles could survive the therapeutic techniques).

3. Preservation of fertility after systemic chemotherapy or bone marrow transplantation in young females, where the ovaries could be removed before the therapy and exposed to the adequate cryopreservation provided by the system till reimplantation after the patient's survival.

4. The system is also suitable for corresponding applications on the testicles.

\section{Conflicts of Interest}

The intellectual properties and the system included in this manuscript belong solely to the author. All rights are preserved solely for the author. Reproduction or use of any of the included intellectual properties requires the written permission of the author. No funding was provided for the development of this work. The author welcomes funding cooperation for experimental and clinical studies.

\section{References}

1. Silber S (2016) Ovarian tissue cryopreservation and transplantation: scientific implications. J Assist Reprod Genet. 33: 1595-1603.

2. Ott J, Nouri K, Stögbauer L, Fischer EM, Lipovac M, et al. (2010) Ovarian tissue cryopreservation for non-malignant indications. Arch of Gynec and Obstet 281: 735-739.

3. Rodriguez-Wallberg KA, Tanbo T, Tinkanen H, Thurin-Kjellberg A, Nedstrand E, Kitlinski ML, et al. (2016) Ovarian tissue cryopreservation and transplantation among alternatives for fertility preservation in the Nordic countries - compilation of 20 years of multicenter experience. Acta Obstet Gynecol Scand 95: 1015-1026.

4. Tsang WH, Chow KL (2010) Cryopreservation of mammalian embryos: Advancement of putting life on hold. Birth Defects Res C Embryo Today 90: 163-175.

5. Santos RR, Amorim C, Cecconi S, Fassbender M, Imhof M, et al. (2010) Cryopreservation of ovarian tissue: an emerging technology for female germline preservation of endangered species and breeds. Anim Reprod Sci 122: 151-163.

6. Silber SJ (2012) Ovary cryopreservation and transplantation for fertility preservation. Mol Hum Reprod 18: 59-67.

7. Candy CJ, Wood MJ, Whittingham DG (1995) Follicular development in cryopreserved marmoset ovarian tissue after transplantation. Hum Reprod 10: 2334-2338.

8. Kardak A, Leibo SP, Devireddy R (2007) Membrane transport properties of equine and macaque ovarian tissues frozen in mixtures of dimethylsulfoxide and ethylene glycol. J Biomech Eng 129: 688-694.

9. Li G, Thirumala S, Leibo SP, Devireddy RV (2006) Subzero water transport characteristics and optimal rates of freezing rhesus monkey (Macaca mulatta) ovarian tissue. Mol Reprod Dev 73: 1600-1611.

10. Schnorr J, Oehninger S, Toner J, Hsiu J, Lanzendorf S, et al. (2002) Functional studies of subcutaneous ovarian transplants in non-human primates: steroidogenesis, endometrial development, ovulation, menstrual patterns and gamete morphology. Hum Reprod 17: 612-619.

11. Ting AY, Yeoman RR, Lawson MS, Zelinski, MB (2011) In vitro development of secondary follicles from cryopreserved rhesus macaque ovarian tissue after slow-rate freeze or vitrification. Hum Reprod 26: 2461-2472.

12. von Schönfeldt V, Chandolia R, Kiesel L, Nieschlag E, Schlatt S, et al. (2011) Advanced follicle development in xenografted prepubertal ovarian tissue: the common marmoset as a nonhuman primate model for ovarian tissue transplantation. Fertil Steril 95: 1428-1434.

13. von Schönfeldt V, Chandolia R, Kiesel L, Nieschlag E, Schlatt S, et al. (2011) Assessment of follicular development in cryopreserved primate ovarian tissue by xenografting: prepubertal tissues are less sensitive to the choice of cryoprotectant. Reproduction 141: 481-490.

14. Yeoman RR, Wolf DP, Lee DM (2005) Coculture of monkey ovarian tissue increases survival after vitrification and slow-rate freezing. Fertil Steril 83: 1248-1254.

15. Amorim CA, Jacobs S, Devireddy RV, Van Langendonckt A, Vanacker J, et al. (2013) Successful vitrification and autografting of baboon (Papio anubis) ovarian tissue. Hum Reprod 28: 2146-2156.

16. Hasegawa A, Mochida N, Ogasawara T, Koyama K (2006) Pup birth from mouse oocytes in preantral follicles derived from vitrified and warmed ovaries followed by in vitro growth, in vitro maturation, and in vitro fertilization. Fertil Steril 86: 1182-1192. 
17. Hashimoto S, Suzuki N, Yamanaka M, Hosoi Y, Ishizuka B, et al. (2010) Effects of vitrification solutions and equilibration times on the morphology of cynomolgus ovarian tissues. Reprod Biomed Online 21: 501-509.

18. Kagabu S, Umezu M (2000) Transplantation of cryopreserved mouse, Chinese hamster, rabbit, Japanese monkey and rat ovaries into rat recipients. Exp Anim 49: 17-21.

19. Suzuki N, Hashimoto S, Igarashi S, Takae S, Yamanaka M, et al. (2012) Assessment of long-term function of heterotopic transplants of vitrified ovarian tissue in cynomolgus 1 monkeys. Hum Reprod 27: 2420-2429.

20. Ting AY, Yeoman RR, Campos JR, Lawson MS, Mullen SF, et al. (2013) Morphological and functional preservation of pre-antral follicles after vitrification of macaque ovarian tissue in a closed system. Hum Reprod 28: 1267-1279.

21. Ting AY, Yeoman RR, Lawson MS, Zelinski MB (2012) Synthetic polymers improve vitrification outcomes of macaque ovarian tissue as assessed by histological integrity and the in vitro development of secondary follicles. Cryobiology 65: 1-11.

22. Ethics Committee of the American Society for Reproductive Medicine (2005) Fertility preservation and reproduction in cancer patients. Fertil Steril 83: 1622-1628.

23. Prest SJ, May FE, Westley BR (2002) The estrogen-regulated protein, TFF-1, stimulates migration of human breast cancer cells. FASEB J 1: 592-594.

24. Seli E, Tangir J (2005) Fertility preservation options for female patients with malignancies. Curr Opin Obstet Gynecol 17: 299-308.

25. Fauser B (2000) Follicle pool depletion: factors involved and implications. Fertil Steril 74: 629-630.

26. Oktem O, Oktay KA (2007) Novel ovarian xenografting model to characterize the impact of chemotherapy agent on human primordial follicle reserve. Cancer Res 67: 10159-10162.

27. Practice Committee of American Society for Reproductive Medicine Practice Committee of Society for Assisted Reproductive Technology (2008) Ovarian tissue and oocyte cryopreservation. Fertil Steril 90: 241-246.

28. Silber S, Gosden RG (2007) Ovarian transplantation in a series of monozygotic twins discordant for ovarian failure. N Engl J Med 356: 1382-1384.

29. Silber S, Kagawa N, Kuwayama M, Gosden R (2010) Duration of fertility after fresh and frozen ovary transplantation. Fertil Steril 94: 2191-2196.

30. Vutyavanich T, Piromlertamorn W, Nunta S (2009) Rapid freezing versus slow programmable freezing of human spermatozoa. Fertil Steril 93: 1921-1928.

31. Karlsson Jens OM, Szurek Edyta A, Higgins Adam Z, Lee Sang R, Eroglu Ali, et al. (2014) Optimization of cryoprotectant loading into murine and human oocytes. Cryobiology 68: 18-28.

32. Amorim CA, Dolmans MM, David A, Jaeger J, Vanacker J, et al. (2012) Vitrification and xenografting of human ovarian tissue. Fertil Steril 98: 1291-1298.

33. Kuleshova LL, Lopata A (2002) Vitrification can be more favorable than slow cooling. Fertil Steril 78: 449-454.

34. Varisli O, Scott H, Agca C, Agca Y (2013) The effects of cooling rates and type of freezing extenders on cryosurvival of rat sperm. Cryobiology.
35. van Eyck AS, Jordan BF, Gallez B, Heilier JF, van Langendonckt A, et al. (2009) Electron paramagnetic resonance as a tool to evaluate human ovarian tissue reoxygenation after xenografting. Fertil Steril 92: 374-81.

36. Keros V, Xella S, Hultenby K, Pettersson K, Sheikhi M, et al. (2009) Vitrification versus controlled-rate freewing in cryopreservation of human ovarian tissue. Hum Reprod 24: 1670-1683.

37. Huang L, Mo Y, Wang W, Li Y, Zhang Q, et al. (2008) Cryopreservation of human ovarian tissue by solid-surface vitrification. Eur J Obstet Gynecol Reprod Biol 139: 193-198.

38. Liu J, Van der Elst J, Van den Broecke R, Dhont M (2002) Early massive follicle loss and apoptosis in heterotopically grafted newborn mouse ovaries. Hum Reprod 17: 605-611.

39. Bedaiwy MA, El-Nashar SA, El Saman AM, Evers JLH, Sandadi S, et al. (2008) Reproductive outcome after transplantation of ovarian tissue: a systematic review. Hum Reprod 23: 2709-2717.

40. Bedaiwy MA, Falcone T (2010) Whole ovary transplantation. Clin Obstet Gynecol 53: 797-803.

41. Israely T, Nevo N, Harmelin A (2006) Reducing ischaemic damage in rodent ovarian xenografts transplanted into granulation tissue. Hum Reprod 21: 1368-1379.

42. Kim SS, Yang HW, Kang HG (2004) Quantitative assessment of ischemic tissue damage in ovarian cortical tissue with or without antioxidant (ascorbic acid) treatment. Fertil Steril 82: 679-685.

43. Sagsoz N, Kisa U, Apan A (2002) Ischaemia-reperfusion injury of rat ovary and the effects of vitamin C, mannitol and verapamil. Hum Reprod 17: 2972-2976.

44. Sapmaz E, Ayar A, Celik H (2003) Effects of melatonin and oxytetracycline in autologous intraperitoneal ovary transplantation in rats. Neuro Endocrinol Lett 24: 350-354.

45. Imthurn B, Cox SL, Jenkin G (2000) Gonadotrophin administration can benefit ovarian tissue grafted to the body wall: implications for human ovarian grafting. Mol Cell Endocrinol 163: 141-146.

46. Jeremias E, Bedaiwy MA, Gurunluoglu R (2002) Heterotopic autotransplantation of the ovary with microvascular anastomosis: a novel surgical technique. Fertil Steril 77: 1278-1282.

47. Jadoul P, Donnez J, Dolmans MM (2007) Laparoscopic ovariectomy for whole human ovary cryopreservation: Technical aspects. Fertil Steril 87: 971-975.

48. Silber SJ, Grudzinskas G, Gosden RG (2008) Successful pregnancy after microsurgical transplantation of an intact ovary. N Engl J Med 359: 2617-2618.

49. Courbiere B, Caquant L, Mazoyer C (2009) Difficulties improving ovarian functional recovery by microvascular transplantation and whole ovary vitrification. Fertil Steril 91: 2697-2706.

50. Onions VJ, Webb R, McNeilly AS (2009) Ovarian endocrine profile and long-term vascular patency following heterotopic autotransplantation of cryopreserved whole ovine ovaries. Hum Reprod 24: 2845-2855.

51. Maffei S, Galeati G, Pennarossa G, Brevini TA, Gandolfi F, et al. (2015) Extended ex vivo culture of fresh and cryopreserved whole sheep ovaries. Reprod Fertil Dev Jun.

52. Mohamed MSA (2015) Translational insights on lung transplantation learning from immunology. Iran J Immunol 12: 156-65. 